\title{
Uma breve análise da possibilidade do Unschooling enquanto proposta metodológica de educação integral para homeschooling no Brasil
}

\author{
A brief analysis of the possibility of unschooling as a methodological proposal for integral education \\ for homeschooling in Brazil
}

Breve análisis de la posibilidad del unschooling como propuesta metodológica de educación integral para homeschooling en Brasil

Recebido: 24/04/2021 | Revisado: 03/05/2021 | Aceito: 07/05/2021 | Publicado: 21/05/2021

Henrique Ribeiro de Araujo
ORCID: https://orcid.org/0000-0002-1172-6689
Instituto Federal de Educação, Ciência e Tecnologia de Mato Grosso, Brasil
E-mail: pastorhenrique@uol.com.br
Edione Teixeira de Carvalho
ORCID: https://orcid.org/0000-0002-1208-3961
Instituto Federal de Educação, Ciência e Tecnologia de Mato Grosso, Brasil
E-mail: edione.carvalho@svc.ifmt.edu.br

\begin{abstract}
Resumo
Unschooling é uma metodologia homeschooling bastante conhecida nos Estados Unidos, mas pouco difundida em território brasileiro. O objetivo deste artigo é analisar a metodologia de unschooling e compará-la à descrição de educação integral de várias autoridades sobre o tema, e das cartilhas de educação integral do Ministério da Educação, e validá-la (ou não) como proposta de educação integral para ensino doméstico no Brasil. Para isso, na metodologia, foi analisada a obra base do fundador do método, John Holt (Holt \& Farenga, 2017), dentre outras, na qual é explicado o que é o unschooling e sua prática, além de examinar e descrever os conceitos de educação integral, no contexto brasileiro, a fim de examinar não apenas a exequibilidade do referido método de ensino no lar, mas também sua eficácia no alcance integral do aluno, nas dimensões afetiva, cognitiva e psicomotora. Como resultado da pesquisa, constatouse que o unschooling é uma metodologia homeschooling que alcança todas as dimensões do aluno, servindo plenamente como tipo de educação integral no Brasil.
\end{abstract}

Palavras-chave: Unschooling; Ensino doméstico; Educação integral; Metodologia; Ensino.

\begin{abstract}
Unschooling is a homeschooling methodology well-known in the United States, but not widespread in Brazilian territory. The purpose of this article is to analyze the unschooling methodology and compare it to the description of integral education by various authorities on the subject, and the integral education booklets of the Ministry of Education, and to validate it (or not) as a comprehensive education proposal. for home education in Brazil. For this, in the methodology, the basic work of the founder of the method, John Holt (Holt \& Farenga, 2017), among others, will be analyzed, in which he explains what is unschooling and its practice, and concepts of integral education will be described and examined, in the context Brazilian, in order to examine not only the feasibility of the aforementioned teaching method at home, but also its effectiveness in the full reach of the student, in the affective, cognitive and psychomotor dimensions. As a result of the research, it was found that unschooling is a homeschooling methodology that reaches all dimensions of the student, fully serving as a type of comprehensive education in Brazil.
\end{abstract}

Keywords: Unschooling; Homeschooling; Integral education; Methodology; Teaching.

\section{Resumen}

La desescolarización es una metodología de educación en el hogar muy conocida en los Estados Unidos, pero no muy extendida en el territorio brasileño. El propósito de este artículo es analizar la metodología de desescolarización y compararla con la descripción de la educación integral por diversas autoridades en la materia, y de los cuadernillos de educación integral del Ministerio de Educación, y validarla (o no) como una propuesta educativa para la educación en el hogar en Brasil. Para ello, en la metodología se analizará el trabajo básico del fundador del método, John Holt (Holt \& Farenga, 2017), entre otros, en el que explica qué es la desescolarización y su práctica, y se examinarán conceptos de educación integral, en el contexto brasileño, con el fin de examinar no solo la viabilidad del mencionado método de enseñanza en el hogar, sino también su efectividad en el alcance integral del estudiante, en las dimensiones afectiva, cognitiva y psicomotora. Como resultado de la investigación, se encontró que la desescolarización es una metodología 
de educación en el hogar que alcanza todas las dimensiones del estudiante, sirviendo plenamente como un tipo de educación integral en Brasil.

Palabras clave: Desescolarización; Educación en casa; Educación integral; Metodología; Ensenãnsa.

\section{Introdução}

Unschooling é um termo criado pelo nova-iorquino John Holt (1923-1985), por volta dos anos 1970 (Laricchia, 2016), que pode ser traduzido como "desescolarização" e significa "como ajudamos as crianças a aprender sem reproduzir as ideias e práticas que aprendemos na escola" (Holt \&Farenga, 2017, p. 17). Em sua obra, Ensine do seu jeito, seu pensamento sobre o unschooling é descrito de forma elucidativa (Holt \& Farenga, (2017). Neste clássico, reeditado diversas vezes, o autor descreve o que é a "desescolarização", suas formas, e alternativas, elucidando o início de sua proposta nos EUA, assim como o status legal da questão, entremeando com muitos exemplos.

Sedlmayr (2014) apresenta um conceito de unschooling um pouco mais amplo, e que talvez seja mais elucidativo em relação ao que é esta metodologia: "Unschooling é uma forma de vida, como muitas outras válidas, que possibilita uma liberdade fora do comum e uma independência das convenções sociais limitadoras, focando-se na ideia de respeito absoluto pela integridade do ser humano" (Sedlmayr, 2014, p. 53). Riley (2018) do Curso Técnico em Meio Ambientedefine o unschooling como um aprendizado infantil através das experiências diárias da vida, e, com cerca de $12 \%$ das famílias americanas o praticando. Holt \& Farenga (2017) defendem enfaticamente que pais têm direito inalienável de educar os filhos, sem o processo escolar, se assim o quiserem.

Holt foi precedido pelo austríaco Ivan Illich (1926-2002) na ideia do processo de desescolarização, na qual, o referido autor publicou a obra Deschooling Society ("Sociedade sem escolas"), em 1971, defendendo o fim do monopólio do ensino por parte das escolas (Illich, 1971). Comentando Illich, Joseph afirma que:

A tese de Illich, cujo mérito avulta na proporção direta do fracasso educacional geral, é que o sistema de ensino não tem por objetivo realmente educar, mas somente distribuir socialmente os indivíduos, por meio do ritual de certificados e diplomas. A escola formal, esta que Illich deseja suprimir, não é um meio de educação, mas um meio de promoção social, fato que as pessoas humildes revelam perceber quando insistem com o Joãozinho: Estude, meu filho, estude... (Joseph, 2008, p. 13).

Seguindo nesta linha, Sedlmayr (2014) ressalta que o conceito de unschooling é bastante complexo, referindo-se a uma "atitude antipedagógica em todas as variantes da vida" (2014, p. 54). Enfatiza-se uma atitude de respeito pela individualidade e cada membro da família deve ter apoio para desenvolver o seu potencial máximo, com especial relevância às necessidades emocionais de cada membro da família, mantendo como prioridade nutrir e salvaguardar o direito à liberdade de cada um (Sedlmayr, 2014). Santos (2019) descreve a diferença entre deschooling e unschooling como o primeiro sendo uma luta nos bastidores escolares e governamentais para definir práticas distintas das atuais práticas escolares, que sejam mais eficientes e eficazes em seus resultados de formação do aluno, enquanto unschooling consistiria na criação de uma prática educativa diferente das atuais práticas hegemônicas que têm sido propostas pela escola. $\mathrm{O}$ unschooling é um deschooling, mas nem todo deschooling é um unschooling (Laricchia, 2016) ou seja, enquanto o unschooling é uma metodologia de aprendizado sem a escolarização, o processo de desescolarização também pode ser feito de outras formas que não apenas pelo unschooling. O deschooling pode também ser compreendido como período de transição do ensino escolarizado para um ensino não escolarizado (Laricchia, 2014).

Apesar de ser categorizada como "metodologia de ensino doméstico" (Moreira, 2017, p. 61), para autores como Zamboni (2020) o unschooling apresenta-se mais como uma "abordagem educativa" que ele denomina de "aprendizagem pela descoberta" (Zamboni, 2020, p. 77), visto não ter um modus faciendi metódico ou material didático específico, mas ter como 
característica central um ensino não escolarizado. É um ensino com um currículo descentralizado, e não centrado no professor (Laricchia, 2016).

Examinar uma metodologia de ensino doméstico neste momento é extremamente pertinente, uma vez que, até memo de maneira forçosa, nesta pandemia incomparável, as famílias brasileiras se depararam inesperadamente com a necessidade de desenvolverem um "quase tipo de ensino doméstico". Inesperadamente, um tipo de ensino remoto foi implantado da noite para o dia no ensino médio e fundamental, sem a capacitação de professores ou a preparação de conteúdo específico no formato adequado ou da estrutura eletrônica necessária - o que a modalidade de ensino a distância oferecida nas faculdades tem feito de forma adequada desde a sua implantação (Silva, 2013). Pais, principalmente de alunos da educação infantil, viram seus filhos migrarem da noite para o dia do ensino presencial para o ensino a distância, muitos sem nunca terem manuseado um computador (Gatti, 2020). Desta maneira, os genitores tiveram que se tornar homeschoolers, pois, na elaboração de grande parte das tarefas passadas por professores de disciplinas diversas para serem feitas durante a aula, pais tinham que estar ao lado do seu filho diante do computador para ajudar a procurar gravuras de revistas, tipos variados de papel, e vários outros materiais didáticos requeridos pelo docente do outro lado da tela. Uma grande parte de pesquisadores já afirma que o ensino pós-pandemia será caracterizado por um processo permanente de hibridização (Pasini; Carvalho \& Almeida, 2020).

Como justificativa, adicione-se ao contexto pandêmico o avanço dos projetos de Lei e de legislações de âmbito local avançando nos estados e na federação em relação ao tema. O Projeto de Lei 2.401, de 2019, de autoria do Poder Executivo, dispõe sobre o exercício do direito à educação domiciliar, alterando a Lei n ${ }^{\circ} .8 .069$, de 13 de julho de 1990 (Estatuto da Criança e do Adolescente), e a Lei n ${ }^{0.9}$ 9.394, de 20 de dezembro de 1996, que estabelece as diretrizes e bases da educação nacional. Este Projeto de Lei (PL) foi apensado ao Projeto de Lei 3.179/2012 (Santos \& Mororó, 2020).

Em 02 de Abril de 2019 foi lançada a Frente Parlamentar do Ensino Doméstico. O ensino domiciliar já foi aprovado como Lei Municipal em Cascavel, Paraná, Lei 7.160 de 25 de setembro de 2020. O Distrito Federal entrou para a história como primeira unidade da Federação a ter lei específica sobre a educação domiciliar. A Lei 6.759, de 16 de dezembro de 2020, já foi sancionada pelo governador Ibaneis Rocha no Distrito Federal. Apesar da lei municipal e da lei do Distrito Federal terem sido sancionadas, e do PL 2401, do poder executivo, de outros sete projetos de lei sobre ensino doméstico estarem em tramitação, já houve diversos reveses no assunto. Em 20 de abril de 2021, foi aprovado, em Guaíra, Paraná, o Projeto de Lei no. 013de 2021, que dispõe sobre o ensino domiciliar no município de Guaíra (ANED, 2021).

Há, porém, reveses sobre o avanço da regulamentação. Vitória, do Espírito Santo, foi a primeira cidade brasileira a aprovar o homeschooling, em abril de 2019, porém Luciano Rezende, então prefeito da capital, vetou a proposta aprovada. A Câmara municipal derrubou o veto; a lei foi promulgada em agosto do mesmo ano, mas a Administração municipal apresentou uma Ação Direta de Inconstitucionalidade (ADI) ao Tribunal de Justiça do estado. A modalidade permanece suspensa por uma liminar desde então. Em Salvador, na Bahia, ocorreu algo semelhante, com a Câmara dos Vereadores aprovando o Projeto de Lei que regulamentava o ensino domiciliar, em Maio de 2020, mas o prefeito ACM Neto vetou, afirmando que o ensino doméstico no estado só poderá existir se houver criação e regulamentação pelo Congresso Nacional por meio de Lei Federal. Em Itaúna, Minas Gerais, outro Projeto de Lei neste sentido foi aprovado pela Câmara, e vetado pelo Prefeito. No Rio Grande do Sul, e Santa Catarina, as Comissões de Constituição e Justiça (CCJs) das Assembleias Legislativas, aprovaram projetos sobre educação domiciliar. No mesmo dia da posse dos novos presidente e vice-presidente do Conselho Estadual de Educação de São Paulo, em 21 de abril de 2021, foi aprovado pelo Conselho e homologado pela Secretaria Estadual de Educação que antecipa-se à possibilidade de aprovação do homeschooling em âmbito federal, enrijecendo sua prática, através da adoção de medidas como: As crianças deverão estar matriculadas em escolas, e aprenderem com profissionais. No dia seguinte, aluna aprovada na Universidade Federal de São Paulo (USP) foi impedida de matricular-se por ter sido homeschooler. Apesar da homologação da Secretaria Estadual de Educação, o texto não tem força de Lei. 
Apesar de várias famílias brasileiras estarem praticando o ensino doméstico, é importante ressaltar que, no Parecer 34/2000, do Conselho Nacional de Educação (CNE), a decisão foi que: "Por enquanto, na etapa a que se refere o pleito, a matrícula escolar é obrigatória, o ensino é presencial e o convívio com outros alunos de idade semelhante é considerado componente indispensável a todo processo educacional" (MEC, 2021). Diante deste fato, é necessário recorrer à justiça para conseguir a possibilidade da autorização para o exercício do ensino doméstico.

Diante deste quadro, é fundamental a análise de propostas metodológicas para a aplicação do ensino doméstico, pois já havendo tanto um município, quanto uma unidade da Federação tendo aprovado esta modalidade, é importante que estudos na área possam estar disponíveis.

O objetivo deste artigo é analisar a metodologia de unschooling e compará-la à descrição de educação integral de várias autoridades sobre o tema, e das cartilhas de educação integral do Ministério da Educação, e validá-la (ou não) como proposta de educação integral para ensino doméstico no Brasil.

Uma vez conceituado o unschooling, vista a necessidade do homeschooling em um tempo pandêmico e atualizado o status legal do ensino doméstico em solo brasileiro, faz-se necessário descrever a metodologia da pesquisa a fim de analisar sua possibilidade de classificação como educação integral.

\section{Metodologia - Caminhos Percorridos}

Como metodologia, a pesquisa que resulta neste artigo pode ser caracterizada como qualitativa, aplicada, exploratória e documental (Prodanov et al., 2013). A pesquisa objetiva responder ao problema central: O unschooling é uma metodologia de ensino doméstico válida como educação integral?

Identificado o problema, torna-se necessária a descrição do que é o unschooling, uma vez que tal metodologia de ensino doméstico é desconhecida dos brasileiros, e até mesmo no meio educacional, de forma geral. Para a resolução do problema, a pesquisa analisa diversas obras acerca do tema, e documentos de fundadores do unschooling, pesquisas estatísticas e descrições de sua prática. A metodologia prossegue examinando os documentos sobre o andamento do processo de legalização de homeschooling no Brasil, e seu status. Tanto a descrição, quanto o processo de legalização através da análise das fontes foi supracitada. Segue-se, então, a descrição e comparação do unschooling com a educação integral, valendo-se do debate entre vários autores e também da análise documental da cartilha do Ministério de Educação sobre o tema - após seu perfilamento - a fim de examinar se o unschooling pode ter características de educação integral e se pode ser considerado como tal.

Uma vez obtidos e analisados os dados, as informações essenciais foram alinhavadas, para proceder-se à discussão e resultados, visando uma classificação ordenada, apresentando também perspectivas variegadas sobre a temática a partir de teóricos referência com a redação do relatório final do artigo.

\section{Resultados e Discussão}

Ao observar a metodologia unschooling e compará-la à descrição de educação integral, conclui-se como resultado que as diversas dimensões do ser (afetiva, cognitiva e psicomotor) são açambarcadas pelo referido método, que pode ser considerada uma boa proposta metodológica de educação integral. Observe-se o porquê na descrição dos resultados, e discussão.

\subsection{A desescolarização de John Holt}

A "desescolarização" de John Holt foi criada para "descrever como ajudamos as crianças a aprender sem reproduzir as ideias e práticas que aprendemos na escola (Holt \& Farenga, 2017, p. 17). O foco do unschooling é aprender a ser, aprender a fazer e aprender a saber (Aldrich, 2011). 
Para Holt e Farenga (2017), há assuntos, tais como trigonometria, que são ensinados em um universo infantil, no qual muitos poucos daquele universo precisarão da utilização daquele conhecimento para lidar com um computador. Conhecimentos como este dificilmente motivam uma criança a aprender e levam também os pais a tirarem os filhos da escola, afinal, "animais são melhores que livros sobre animais" (Aldrich, 2011, 9, p. 219). Laricchia (2016) afirma que conhecimentos como este, dos quais ouvimos, mas não lembramos mais atualmente como adultos, significa que, na realidade, não entendemos, e foram não proveitosos para nossa vida prática.

Segundo o referido professor (Holt \& Farenga, 2017), pais que tiram seus filhos da escola por três razões principais: Pais creem ser sua responsabilidade educar os filhos, querem vê-los aprender e não querem que seus filhos sejam prejudicados em alguma dimensão: "Crianças aprendem o que querem" (Holt \& Farenga, 2017, p. 84), e querem o que amam (Aldrich, 2011). Observando os motivos dos pais, e o desejo das crianças, Holt propôs um tipo de ensino que fosse "desescolarizado", no qual, privilegiando a experiência, e a vontade infantil de aprender o que se tem interesse, os pais ensinem aos filhos de forma mais eficaz; o ensino se torna customizado (Aldrich, 2011), mais prático, aplicável e experimentável (Laricchia, 2016). Desta forma, um dos principais focos do unschooling tem sido a dicotomia "aprender x ensinar", em que advoga-se que, na realidade, o processo educacional não deve basear-se no que o professor quer ensinar, mas no que o aluno quer aprender (Laricchia, 2012).

Gray e Riley afirmam que o aprendizado privilegiando a experiência e o meio ambiente, para as crianças da escola entende-se como a interação com os professores, com os livros textos e com os colegas, entretanto, o unschooling propõe-se a ser um movimento "contra-cultural", no sentido de que, enquanto escolas seguem um currículo categórico, previamente programado, o unschooling enfatiza a necessidade da criança conhecer o "mundo real", ter experiências com maior liberdade, não ter um currículo tão inflexível, e não passar horas a fio na escola com tantos dias separada da convivência familiar (2013, p. 2).

Holt não faz diferença entre viver e aprender (Moreira, 2017). Para ele, disjungir estas ações é prejudicial ao infante. Ele afirma que "o bom desempenho escolar das crianças muitas vezes está relacionado a conversas agradáveis sobre atualidades durante as refeições" (Holt \& Farenga, 2017, p. 39). Com a desescolarização, "nossos filhos vivem no mundo real todos os dias e aprendem o que precisam ou têm interesse ao longo do caminho [...] Eles participam da vida no mundo real desde o início [...] Quando o foco é viver, em vez de ser guiada por currículos, as crianças que não escolhem são guiadas pela curiosidade" (Laricchia, 2016, p. 12). Laricchia denomina este tipo de aprendizado de "currículo da curiosidade" (2016, p. 12).

O professor norte-americano critica a União Americana pelas Liberdades Civis afirmando que a mesma "tratou como questão de liberdade civil o direito de ir à escola, mas não o direito de não ir" (Holt \& Farenga, 2017, p. 48). Ele também lembra que médicos aprendem que uma prioridade sua é não causar danos ao paciente, e os tratadores de animais não devem causar dano, porém, reconhecendo que a escola é mesquinha, competitiva e esnobe tantas vezes, mesmo assim enviam seus filhos, pois "isso é o que eles vão enfrentar na vida" - argumentam a Holt, que questiona: "Mas será que não há outra forma ou idade certa?" (Holt \& Farenga, 2017, p. 80).

Algumas características do unschooling são a ênfase na motivação intrínseca do aluno, a observação das competências usando a teoria da avaliação cognitiva como uma base para o estilo de vida, a ênfase na autonomia do aluno, o fortalecimento dos graus e relacionamentos parentais, além do já referido foco no aprendizado através das experiências diárias do aluno (Riley, 2018).

Holt (2017) propõe um tipo de aprendizado que seja a continuidade do que os pais já fazem diariamente com os filhos:

A maior parte do que elas precisam já tem sido dada pelos pais desde que nasceram. Elas precisam de acesso. Às vezes de uma conversa sincera, séria e sem pressa; ou às vezes de piadas e brincadeiras; outras vezes de ternura, compreensão e conforto. Elas precisam, em boa parte de sua vida, ou, pelo menos, não se sentir fora dela. Em resumo, ir a alguns dos lugares a que você vai, ver e fazer algumas das coisas pelas quais você se interessa, conhecer alguns de seus amigos, 
saber o que você fazia quando era pequeno e antes delas nascerem. Elas precisam que as perguntas que fazem sejam respondidas, ou, ao menos, ouvidas com atenção - se você não souber responder, diga 'eu não sei'. Elas precisam conhecer cada vez mais adultos cuja tarefa principal na vida não seja cuidar de crianças. Elas precisam de alguns amigos da mesma idade, mas não dezenas; dois ou três, no máximo, seis, esse é o número máximo de verdadeiros amigos que uma criança consegue ter de uma só vez. Talvez elas precisem, sobretudo, de privacidade, tempo a sós, tempo sem nada para fazer $(2017$, p. 89$)$.

Holt e Farenga (2017) enfatizam a necessidade de acesso das crianças ao mundo real, com tempo e espaço suficientes para refletir sobre suas experiências, usando fantasia e brincadeira para dar sentido às experiências vividas, com ajuda, mapas, guias e o que puderem ter de orientação para chegarem onde querem chegar, e, na sua perspectiva: "as escolas não são capazes de oferecer experiência" (Holt \& Farenga, 2017, p. 142). Pelo foco no aprendizado diário, e pela ênfase na experiência, Laric chia chama também o unschooling de "aprendizado pela vida" (2016, p. 9).

O mestre estadunidense conceitua inteligência como "não é a medida do quanto sabemos fazer, mas de como nos comportamos quando não sabemos o que fazer. Ela está relacionada à nossa habilidade de formular perguntas importantes e, então, encontrar meios de obter respostas úteis (Holt \& Farenga, 2017, p. 201). Desde perguntas sobre o que comer no café da manhã, banana com aveia ou pão com manteiga, definir se se deseja jogar vôlei ou futebol, ir para a aula de natação em um clube ou nadar em um rio, dentre outras, ajudam a entender a vida, a explorar a si mesmo, e motivar o aluno no entendimento de quem ele é (Laricchia, 2016).

O unschooling não tem um currículo rígido pré-definido, visto que eu propósito é aprender através das experiências diárias da vida (Riley, 2018). Porém, há assuntos que são comuns na metodologia unschooling, que é considerado um currículo unschooling inclui: (1) Habilidades básicas de comunicação: Letras: Leitura silenciosa e oral; habilidades de escuta; contar histórias; homônimos; sinônimos e antônimos; escrita de cartas, história e poemas à mão, por ditado ou digitação; utilização de dicionários para significado e ortografia; utilização de enciclopédias; competências para utilizar a biblioteca; uso de pontuação básica; utilização de tabelas de conteúdos e índices; e habilidades em informática; em Matemática: Contar e escrever os números por unidades, dezenas, centenas e milhares; adição e subtração com números de um e dois algarismos; saber as horas e usar o calendário; valor de moedas e cálculo de troco; e o valor de centímetros, metros e quilômetros; (2) Cidadania, História e Governo: Atualidades: Assembleia popular; viajar por regiões; feriados nacionais; leitura de mapas mundiais, com nome de oceanos, continentes, países e estados; (3) Educação física e educação para a saúde: Esportes: Ciclismo, caminhadas, escalada de árvores, natação, ginástica; Educação em saúde: Primeiros socorros básicos para cortes, arranhões, queimaduras, distensões, torções, tratamento da gripe comum, cuidado com os dentes; segurança no trânsito, planejamento de refeições familiares e preparação de comida; (4) Literatura: Romances dos séculos 19 e 20, poesia e mitologia grega; (5) Ciências naturais: Sementes, plantas, flores, pássaros comuns, sol, lua, estrela, constelações básicas; estações do ano; nuvens; fogo e temperatura; animais de criação; (6) Belas-artes: Desenho, pintura; computação gráfica; produção de roupas e lenços para bonecas e vestuário; frequentar concertos e peças; ouvir música em casa; canto (Holt \& Farenga, 2017, p. 287). Aldrich (2011) adiciona outros elementos tão variados quanto: Preparação de refeições, uso de tecnologias, longos períodos de reflexão, visitas a diversos tipos de trabalhos diferentes e observação de profissionais em exercício (no hospital, na padaria, nas delegacias de polícias, etc.), ler o que pessoas "normais" leem, uso de jogos de computador, exercícios de mais construção para evitar mais consumo.

Mesmo com este currículo bastante amplo, Zamboni (2020) entende que há uma necessidade maior de rigor metódico, do que a ampla liberdade enfatizada e preconizada por Holt: "Há, contudo, habilidades essenciais, como a leitura, a escrita e o cálculo, que devem ser adquiridas por treino metódico e são base para a desenvoltura da mente no futuro" (Zamboni, 2020, p. 78).

Dentre as principais dificuldades para a prática do unschooling, segundo pesquisa capitaneada por Gray \& Riley (2018), nos Estados Unidos, estão: Sentimentos de pressão social ou crítica pela decisão de desescolarizar; dificuldade por parte dos pais 
para se livrar de suas próprias crenças sobre o valor da escola ou do currículo; conciliar tempo, carreira e renda; dificuldade para arranjar oportunidades para seus filhos se socializarem com outros, e; questões legais associadas à desescolarização. Os autores inda perguntaram sobre as vantagens da prática do unschooling, e, as respostas elencadas foram: Maior eficiência e entusiasmo com o aprendizado através de algo mais relevante para a vida; nível maior de curiosidade; maior felicidade, menos estresse, mais autoconfiança e agradabilidade, e que, na opinião dos pais, todos estes fatores geram uma vantagem social em relação aos relacionamentos e desafios da vida, e não uma desvantagem, como algumas pessoas poderiam pensar, em relação à sociabilidade.

Analisando os dados concernentes ao unschooling, percebe-se, tanto pelo seu currículo, quanto pela sua filosofia educacional, que tanto a dimensão cognitiva, quanto a afetiva e a psicomotor são abarcadas pelo método de desescolarização. Desta forma, chega-se ao seguinte resultado:

Na dimensão afetiva, conforme visto supracitadamente, o unschooling enfatiza a atenção às emoções do aluno. Cuidar com ternura, compreensão e conforto é entendido como fundamental para o bom aprendizado do aluno. A presença das belasartes no currículo, com desenho, pintura, música e outras artes ajudam o pai homeschooler a trabalhar a percepção, sensibilidade e toda a dimensão afetiva de seus filhos. Os romances dos séculos 19 e 20, assim como a poesia, lidas e replicadas pelos filhos, fomentam a motivação na produção criativa e na apreciação do belo. A possibilidade da atenção ser dada exclusivamente ao filho como aluno é bem maior do unschooling do que em uma grande classe, conforme atesta Tardif, para quem o objeto de trabalho de um professor decorre de sua dimensão afetiva, pois "um componente emocional manifesta-se inevitavelmente, quando se trata de seres humanos. Quando se ensina, certos alunos parecem simpáticos, outros não. Com certos grupos, tudo caminha perfeitamente bem; com outros, tudo fica bloqueado. Uma boa parte do trabalho docente é de cunho afetivo, emocional" (Tardif, 2014, p. 130). Laricchia (2013) afirma que é uma característica bastante comum ao unschooling o robustecimento no relacionamento entre pais e filhos, e que, corolariamente, reverbera em crianças com forte autoestima e forte autoconfiança.

O alcance da dimensão cognitiva é bastante evidente no currículo. A ênfase na leitura e contação de histórias incentiva a memorização através da compreensão e repetição. A comparação entre os homônimos, sinônimos e antônimos, além de aumentar o vocabulário, auxilia o aluno no raciocínio lógico, capacidade de diferenciação e organização em categorias mentais. As habilidades em informática e matemática, tais como contagens, utilização de sistemas de metragem, e valores consolida no aluno seu raciocínio lógico.

No aspecto psicomotor, a ênfase nas experiências é extremamente importante para a amalgamação do ensino na vida do aluno, a fim de que o conceito aprendido tenha sua aplicação de imediato, e a lição se torne mais prática. As conversas durante as refeições também podem ser um excelente momento de assentamento do conhecimento em um ambiente leve e agradável, e até mesmo um momento de instrução das consequências benéficas dos alimentos no aspecto físico. Os esportes diversos propostos - ciclismo, caminhadas, escaladas de árvores, natação, ginástica, dentre outros - contemplam bastante a dimensão psicomotora, além dos cuidados com a saúde física e psicológica em geral.

A filosofia da desescolarização parte do pressuposto das crianças como sendo naturalmente curiosas e possibilita inúmeras possibilidades da criança ser mais autônoma em seu aprendizado. A experiência de diversos unscoolers que já fizeram ou estão fazendo curso superior mostrou que a desescolarização os beneficiou para o ensino superior e para a escolha de suas carreiras, tendo promovido a eles o senso de responsabilidade social, automotivação e desejo de aprender (Rilery \& Gray, 2015).

O resultado da análise de dados, constatou que o unschooling envolve as dimensões afetiva, cognitiva e psicomotor da criança, além de envolvê-las de forma direta nas questões sociais e relacionais, enfatizando relacionamentos sólidos e duradouros com família, amigos e Sociedade. Diante disso, examine-se agora a educação integral, para analisar se o unschooling pode ser assim caracterizado. 


\subsection{Educação integral}

Educação integral é o tipo de educação que visa desenvolver todas as dimensões do ser: Afetivo, cognitivo e psicomotor. A "educação integral" pode ser entendida como a oferta de uma formação completa para o indivíduo, considerando-o em sua condição multidimensional (Coelho, 2009).

O Ministério de Educação (MEC) produziu um texto referência sobre educação integral, no qual afirma que:

A educação integral se caracteriza pela ideia de uma formação 'mais completa possível' para o ser humano, embora não haja consenso sobre o que se convenciona chamar de 'formação completa' e, muito menos, sobre quais pressupostos e metodologias a constituiriam. Apesar dessa ausência de consenso, é possível afirmar que as concepções de Educação integral circulantes até o momento, fundamentam-se em princípios político ideológicos diversos, porém, mantêm semelhanças em termos de atividades educativas (MEC, 2009).

Na linha das perspectivas do MEC (2009), Paiva, Azevedo e Coelho (2014) lembram que compreender o significado de educação integral requer a consciência de que não há hegemonia quando ao seu conceito.

O termo "integral" significa "completo", "inteiro", e qualquer tipo de educação que se pretenda "integral" deve tentar açambarcar as dimensões cognitiva, afetiva e psicomotor do aluno. Nos conceitos atuais de educação integral, percebe-se que se fala de "relações" tal como afirmam Paiva, Azevedo e Coelho, falando dos diversos vieses de educação integral: "Educação integral na perspectiva de promover proteção integral a crianças e adolescentes; educação integral a partir da oferta de um currículo escolar integrado, e; educação integral associada ao tempo integral, ou seja, a ampliação das horas diárias em que o aluno permanece na escola" (Paiva, Azevedo \& Coelho) 2014, p. 49).

Pestana (2014) explica tal dicotomia nos conceitos, ressaltando que há duas perspectivas básicas ao olhar o aluno como integral: (1) O desenvolvimento do processo educativo açambarcando todas as dimensões do ser humano, e, neste caso, ela as enumera como: cognitiva, estética, ética, física, social e afetiva, enfatizando que este tipo de formação integral que foca o indivíduo deve englobar todos os seus aspectos, e; (2) O sujeito da educação integral, quando trazido para o âmbito da Sociedade, deve ser compreendido como um ser multidimensional, que tem uma série de expectativas e exigências em relação ao contexto, assim sendo, a educação integral deve ter objetivos que construam relações. Neste último sentido, é o que Gadotti chama de "educação cidadã” (Gadotti, 2009, p. 9).

O tempo integral é prediletado nas discussões e nos defensores da educação integral, buscando nos Centros Integrados de Educação Pública (CIEPs) e nos Centros Educacionais Unificados (CEUS), de Rio de Janeiro e São Paulo, respectivamente, e na Lei de Diretrizes e Bases da Educação (LDB,1996), seu respaldo maior (Rosa \& Silva, 2014). Maurício (2009, p. 16) faz um histórico do debate sobre o tempo integral na escola de educação integral, congruindo sua atenção nos antigos CIEPs fluminenses, e, a partir daí, descreve a concepção de educação integral. Segundo Maurício: “A concepção de educação integral com a qual partilhamos, que embasa a proposta de extensão do tempo escolar diário, reconhece a pessoa como um todo e não com um ser fragmentado, por exemplo, entre corpo e intelecto" (Maurício, 2009, p. 27). Para a autora, mais tempo da criança na escola implicará em maior igualdade de condições, pois a criança terá mais tempo para adquirir nos hábitos, valores e conhecimentos para exercer seu direito de cidadã (Maurício, 2009).

Recrudescendo a tempos bem mais anteriores, Coelho (2009) busca na Paideia grega as raízes da educação integral, para, depois disso buscar referências na Revolução Francesa, no projeto de Lepeletier, que propunha uma educação radicada na formação integral, consistindo na aquisição e desenvolvimento das faculdades físicas, intelectuais e morais de cada indivíduo. Após estas duas referências, a professora supracitada se atém mais ao Brasil, pontuando Anísio Teixeira e o Manifesto dos Pioneiros da Escola Nova, de 1932, como um documento referência na educação integral, que propunha: Programa completo de leitura, aritmética, escrita, ciências físicas e sociais, artes industriais, desenho, música, dança, educação física, saúde e alimento à criança, para depois passar à conhecida proposta dos CIEPs, na década de 1980, no estado do Rio de Janeiro (Coelho, 2009). 


\subsection{O unschooling é uma metodologia de ensino doméstico válida como educação integral?}

Diante da análise de dados, e da exposição conforme supracitado, o resultado da pesquisa é que o unschooling é uma metodologia de ensino doméstico válida como educação integral. Sua filosofia educacional, seu currículo, e o depoimento de seus participantes, quando comparados e examinados à luz de conceitos de educação integral, coadunam-se, açambarcam e englobam de forma plena e completa a concepção de educação integral.

A educação integral, conforme os conceitos de Coelho (2009), do Ministério da Educação (2009) ou de Paiva, Azevedo e Coelho, preconiza o alcance da criança em todas as suas dimensões (afetiva, cognitiva e psicomotor), e, no unschooling isto acontece. Além de um currículo conforme proposto supracitado, a ênfase na aplicação por meio das experiências, os passeios e saídas diversos sugeridos, a possibilidade de ensino diário oferecido e desenvolvido pelos próprios pais junto aos filhos, e a liberdade de ter a incorporação de assuntos diversos do dia a dia incorporados à rotina estudantil do aluno, proporcionam grande riqueza, com a exclusividade e particularidade do ensino ser lecionado de forma individualizada, em sua própria casa (Zamboni, 2016), com todo afeto e carinho que lhos cerca, por parte dos pais. Maurício (2009) mesma constata que "a criança vai se desenvolver de qualquer maneira, com escola ou sem ela, com mais tempo ou não no ambiente escolar - o processo educativo se fará de alguma forma" (Maurício, 2009, p. 27), ou seja, fora do ambiente escolar, mas com o acompanhamento educacional devido, a criança poderá se desenvolver plenamente, e até mais. Brandão (2001) também lembra que: "Não há uma forma única nem um único modelo de educação; a escola não é o único lugar onde ela acontece e talvez nem seja o melhor; o ensino escolar não é a sua única prática e o professor profissional não é o seu único praticante" (Brandão, 2001, p. 8).

Maurício (2009) propõe um tipo de educação integral, nas escolas públicas, em que o aluno deva passar os turnos da manhã e da tarde na escola - o que a autora chama de "tempo integral", ou seja, uma "educação integral em tempo integral", afirmando que hábitos como escovação de dentes, educação física, refeição, discussões críticas em sala de aula precisam de tempo integral para serem desenvolvidos, porém a realidade é que isto não ocorre na maioria absoluta das escolas públicas brasileiras. Mas com o método unschooling, no homeschooling, é muito mais provável acontecer.

Ainda segundo Maurício, hábitos devem ser aprendidos na escola, uma vez que "nem todos os pais, menos ainda os avós que criam muitos de nossos alunos, passaram pela escola" (Maurício, 2009, p. 28), porém, esta perspectiva é obsoleta, uma vez que o Brasil tem aumentado gradativamente sua taxa de alfabetização, subindo de 6,8\% em 2018 para 6,6\% em 2019 (IBGE, 2021). É evidente, e de conhecimento amplo que ser alfabetizado ou ter "passado por uma escola" não significa necessariamente aprendizado, mas o aprendizado também não está restrito ao saber escolar.

Mantendo seu foco na educação integral em tempo integral, Maurício afirma também que a escola é um "laboratório de soluções" (Maurício, 2009, p. 28), e com uma convivência longa e diária, poderiam ser formuladas condições coletivas para caminhos produtivos, porém, Holt e Farenga (2017), Gatto (2019) e Bluedorn (2016) apresentam uma extensa lista de contraargumentações em relação a escola ser um "laboratório de soluções", dentre elas, a violência, o bullying, as pressões de professores, a atmosfera de rivalidade, dentre outros. Zamboni ainda chama atenção para o fato de que "o Brasil é o campeão mundial, segundo pesquisa da OCDE, na violência contra professores, dos quais 12,5\% são vítimas semanalmente e $84 \%$ afirmam tê-la presenciado alguma vez ao longo da carreira" (Zamboni, 2020, p. 15).

Ingst (2020), professora de Literatura espanhola na Universidade de Lund, na Suécia, reconhecida mundialmente na área educacional, com vasta experiência de ensino na Finlândia e Suécia, analisando o sistema educacional finlandês, informa que as aulas são de 45 minutos, e o horário de ensino não é integral, e aponta os problemas centrais da educação, não como sendo de tempo, e nem de recursos, mas de cânon - não sabemos o que ensinar - e de sujeito - não temos pessoas tão capazes em ensinar. "Se um país não pode recrutar bons professores e retê-los no sistema educacional, é improvável que consiga ou que mantenha uma boa qualidade em seu sistema educacional" (Ingst, 2019, p. 27). Educação integral não necessariamente significa 
tempo integral dentro de uma escola, mas sim, aprendizado em todas as dimensões da vida, a todo o momento de seu viver. É isto que o unschooling propõe.

\section{Considerações Finais}

Unschooling ou desescolarização é uma metodologia e filosofia educacional (Gray \& Riley, 2013), que preconiza um ensinamento voltado para a vida, fora do ambiente escolar. Não é tão conhecido no Brasil pelo simples fato do ensino doméstico ainda não ser legalizado nacionalmente, e o unschooling ser um de seus métodos. O Projeto de Lei 2.401/2019, de autoria do Poder Executivo, é o principal, dentre vários que tramitam sobre o tema, e tornou-se bastante debatido durante este período de pandemia da COVID-19.

Após descrever e exemplificar o unschooling e a educação integral, a pesquisa analisou ambos para resolver o problema: É o unschooling uma metodologia válida de educação integral enquanto homeschooling no Brasil? O resultado apresentado pela pesquisa foi que o unschooling é uma proposta metodológica válida de educação integral para homeschooling no Brasil, por seu conteúdo, currículo, e exemplos açambarcarem todas as dimensões do aluno: afetiva, cognitiva, psicomotora, e também ter propostas relacionais com amigos, família e Sociedade. Destarte, a pesquisa conseguiu responder ao problema introdutoriamente levantado e também ampliou a compreensão sobre o assunto, tão pouco debatido em território nacional, uma vez que, conforme supracitado, o ensino doméstico ainda não foi legalizado no Brasil

Na pesquisa também percebeu-se que o conceito de educação integral não é tão uniforme quanto se supunha, apresentando outros problemas a serem resolvidos, tais quais: Se é necessário uma educação integral de tempo integral escolarizada, se a educação integral envolve apenas o indivíduo ou também sua relação com a Sociedade, o unschooling com sua filosofia educacional de ampla liberdade ao aluno poderá ser contextualizado aos pais homeschoolers brasileiros em caso de legalização do ensino domiciliar no Brasil?

As obras de Illich (1971) e Holt e Farenga (2017) são essenciais à compreensão das propostas de deschooling e unschooling, assim como de sua diferenciação, e as cartilhas do MEC (2009) sobre educação integral e de Coelho (2009) são ainda hoje referências no debate sobre os assuntos propostos, além de diversas obras, e artigos, dissertações e teses que têm se multiplicado sobre o ensino doméstico, tais como os trabalhos de Santos (2019) e Santos (2020), e o acompanhamento dos Projetos de Lei que se encontram tramitando no Congresso neste momento.

Trabalhos futuros sobre outras metodologias de homeschooling são fundamentais. Neste artigo for abordado um único método: O unschooling. Porém métodos como o Charlotte-Mason, o Trívio, e tantos outros mais são praticamente desconhecidos do Brasil. Se, neste momento, há tantos Projetos de Lei tramitando no Congresso Nacional sobre o tema, por que não anteciparse no preparo de apresentação de propostas metodológicas já existentes nas mais de cinquenta nações que adotam a modalidade do ensino domiciliar, e analisar os pormenores, nuances e benesses de cada uma das propostas?

De forma interessante e envolvente, a reflexão de Cortella, ex-secretário de Educação do município de São Paulo, é um convite a todos os professores brasileiros a conhecerem um pouco mais tanto do unschooling quanto do homeschooling, quanto o filósofo ensina: "Caminhos novos a serem trilhados exigem a inteligência contida na flexibilidade. Ser flexível é diferente de ser volúvel. O volúvel muda de postura a qualquer momento, em função de movimentos ou 'ventos' que não entende. Já a pessoa flexível é aquela que é capaz de alterar a própria convicção ou rota a partir de uma reflexão que leve em conta o diverso ou o inédito" (Cortela, 2018, p. 35).

\section{Referências}

Aldrich, C. (2011). Unschooling rules. Austin, TX: Greenleaf Book Group Press.

Associação Nacional de Ensino Doméstico (ANED). Últimas notícias. Aprovado em primeira votação o PL 013/2021, a favor da educação domiciliar no ensino de Guaíra/PR. <https://www.aned.org.br/index.php/component/content/article/21-blog/conteudo-livre-blog/178-aprovacao-pl-013-2021?Itemid=137>. 
Bluedorn, H. \& Bluedorn, L. (2016). Ensinando o Trivium. Volume 1: O Trivium teórico. Monergismo.

Brandão, C. (2001). O que é educação. Brasiliense.

Brasil. MEC - Ministério Da Educação E Cultura. (2009). Educação integral: Texto referência para o debate nacional. MEC, Secad.

MEC - Ministério Da Educação E Cultura. Parecer 34/2000. < http://portal.mec.gov.br/cne/arquivos/pdf/pceb34_00.pdf >.

Câmara dos Deputados. Projeto de Lei 2401/2019. Dispõe sobre o exercício do direito à educação domiciliar, altera a Lei no 8.069 , de 13 de julho de 1990 Estatuto da Criança e do Adolescente, e a Lei $\mathrm{n}^{\circ}$ 9.394, de 20 de dezembro de 1996, que estabelece as diretrizes e bases da educação nacional. <https://www.camara.leg.br/proposicoesWeb/fichadetramitacao?idProposicao=2198615 >.

Coelho, L. M. C. C \& Portilho, D. B. (2009). Educação integral, tempo integral e políticas públicas: Reflexões sobre concepções e práticas. In: COELHO, Lígia Martha Coimbra da Costa (Org.). Educação integral em tempo integral: Estudos e experiências em processo. FAPERJ, p. 89-99.

Cortella, M. S. (2018). Nós e a escola: Agonias e alegrias. Vozes.

Gadotti, M. (2009). Educação integral no Brasil: Inovações em processo. Instituto Paulo Freire.

Gatti, B. A. (2020). Possível reconfiguração dos modelos educacionais pós-pandemia. Estud. av., 34 (100), 29-41.

Gatto, J. T. (2019). Emburrecimento programado: O currículo oculto da escolarização obrigatória. CEDET.

Gray, Peter \& Riley, Gina (2013). Journal of Unschooling and Alternative Learning. The Challenges and Benefits of Unschooling. According to 232 Families Who Have Chosen that Route, 7 (14), 1-27. <https://cdn2.psychologytoday.com/assets/JUAL\%202013\%20Unschooling\%20Survey\%20art..pdf>.

Holt, J. \& Farenga, P. (2017). Ensine do seu jeito: O livro de John Holt sobre educação domiciliar. Kírion.

Illich, I. (1971). Deschooling Society: Today's most controversial revolutionary gives his prescription for remoking schools to meet our human needs. Harrow books.

Ingst, E. (2019). Educação: Guia para perplexos. CEDET.

Ingst, E. (2020). A boa e a má Educação: Exemplos internacionais. CEDET.

Instituto Brasileiro de Geografia e Estatística (IBGE). Pesquisa Nacional por Amostra de Domicílio: Educação. <https://www.ibge.gov.br/estatisticas/sociais/educacao.html>.

Joseph, M. (2008). O Trivium: As artes liberais da lógica, da gramática e da retórica. É realizações.

Laricchia, P. (2012). Free to learn: Five Ideas for a Joyful Unschooling Life. Living Joyfullt Enterprises.

Laricchia, P. (2013). Free to live: Create a Thriving Unschooling Home. Living Joyfullt Enterprises.

Laricchia, P. (2014). Life through the lens of Unschooling: Living Joyfullt Enterprises.

Laricchia, P. (2016). What is unschooling? Living and Learning without School. Living Joyfullt Enterprises.

Lei $\mathrm{n}^{\circ} \quad 6.759$ de 16/12/2020. (LEGISWEB) Institui a educação domiciliar no Distrito Federal e dá outras providências. <https://www.legisweb.com.br/legislacao/?id=406099\#: :text=Institui\%20a\%20educa\%C3\%A7\%C3\%A3o\%20domiciliar\%20no\%20Distrito\%20Federal\%20 e $\% 20 \mathrm{~d} \% \mathrm{C} 3 \%$ A $1 \% 20$ outras\%20provid\%C3\%AAncias.\&text=Art.,educa\%C3\%A7\%C3\%A3o\%20domiciliar\%20no\%20Distrito\%20Federal.\&text=\%C2\%A7 $\% 203 \%$ C2\%BA\%20A\%20educa\%C3\%A7\%C3\%A3o\%20domiciliar,utilitarista\%20ou\%20por\%20conveni\%C3\%AAncia\%20circunstancial.>.

Lei $\mathrm{n}^{\circ} 7.160$ de 25 de Setembro de 2020. Dispõe sobre educação domiciliar (homeschooling) no município de Cascavel e dá outras providências. Atos do Poder Legislativo de Cascavel. <http://www.cascavel.pr.gov.br/anexos/2020092817033302.pdf_>.

Lei no 9.394 de 20 de dezembro de 1996. Dispõe sobre as diretrizes e bases da educação nacional. <http://www.planalto.gov.br/ccivil_03/leis/19394.htm>.

Maurício, L. V. (2009). Escritos, representações e pressupostos da escola pública de horário integral. In: Maurício, L. V. (Org.). Educação integral e tempo integral. Revista Em Aberto. Brasília: Ministério da Educação \& INEP, 22 (80), 15-31, abril.

Moreira, A. M. (2017). O direito à educação domiciliar. Monergismo.

Paiva, R. S. P., Azevedo, D. S. \& Coelho, L. M. C. C. (2014). Concepções de Educação Integral em propostas de ampliação do tempo escolar. Juiz de Fora: UFJF, 16(1). Instrumento: Revista de estudo e pesquisa em educação. <https://periodicos.ufjf.br/index.php/revistainstrumento/article/view/18892>.

Pasini, C. G. D., Carvalho, E. \& Almeida, L. H. C. (2020). A educação híbrida em tempos de pandemia: Algumas considerações. Santa Maria: Observatório Socioeconômico da COVID-19, projeto realizado pelo Grupo de Estudos em Administração Pública, Econômica e Financeira (GEAPEF) da Universidade Federal de Santa Maria (UFSM), 2020. < https://www.ufsm.br/app/uploads/sites/820/2020/06/Textos-para-Discussao-09-Educacao-Hibrida-em-Tempos-dePandemia.pdf $>$.

Pestana, S. F. P. (2014). Afinal, o que é educação integral? Revista contemporânea de Educação, 9 (17), $24-41$.

Prodanov, C. C. \& Freitas E. C. (2013), Metodologia do trabalho científico: Métodos e técnicas da pesquisa e do trabalho acadêmico. (2a ed.), Universidade Feevale. 
Research, Society and Development, v. 10, n. 6, e8210615429, 2021

(CC BY 4.0) | ISSN 2525-3409 | DOI: http://dx.doi.org/10.33448/rsd-v10i6.15429

Rilery, G. \& Gray, P. (2015). Grown Unschoolers' Experiences with Higher Education and Employement: Report II on a Survey of 75 Unschooled Adults.

Riley, Gina. European Journal of alternative education studies. Unschooling: A direct educational application of Deci and Ryan's (1985) self determination theory and cognitive evaluation theory, 3(1), 54-62, 2018. <https://www.researchgate.net/publication/323880246_UNSCHOOLING_A DDI REC T_EDUCATIONAL_APPLICATION_OF_DECI_AND_RYAN'S_1985_SELF_DETERMINATION_THEORY_AND_COGNITIVE_EVALUATION_THE ORY/link/5ab10e21a6fdcclbc0beeb21/download>

Rosa, A. V. N. \& Silva, Luisa Figueiredo do Amaral (2014). Educação integral e(m) tempo integral: Diálogos sobre uma didática sobre uma didática para o pleno desenvolvimento do educando. Ceará: EdUECE. Livro 3 do Encontro Nacional de Didática e Prática de Ensino (EdUECE). Didática e prática de ensino na relação com a Sociedade. <http://www.uece.br/endipe2014/ebooks/livro3/200\%20EDUCA\%C3\%87\%C3\%830\%20INTEGRAL\%20E\%20M\%20TEM PO\% 20INTEGRAL\%20DI\%C3\%81LOGOS\%20SOBRE\%20UMA\%20DID\%C3\%81TICA\%20PARA\%20O\%20PLENO\%20DESENVOLVIM ENTO\% 20D O\%20EDUCANDO.pdf>.

Santos, A. L. (2019). Educação domiciliar ou lugar de criança é na escola? Uma análise sobre a proposta de homeschooling no Brasil. UFRJ. Dissertação de Mestrado. <https://ppge.educacao.ufrj.br/dissertacoes2019/dALINE\%20LYRA\%20DOS\%20SANTOS.pdf>.

Santos, M. C. \& Mororó, L. P. (2020). Homeschooling no Brasil: Rumo a uma possível regulamentação nacional? ANPED - Associação Nacional de Pósgraduação e Pesquisa em Educação. XXV EPEN - Encontro de Pesquisa Educacional do Nordeste - Reunião Científica da ANPED. Faculdade de Educação da UFBA. <http://anais.anped.org.br/regionais/sites/default/files/trabalhos/20/8318-TEXTO_PROPOSTA_COMPLETO.pdf >.

Silva, R. S. (2013). Gestão de EaD: Educação a distância na era digital. Novatec.

Tardif, M. (2014). Saberes docentes e formação profissional. (17a ed.). Vozes.

Sedlmayr, A. (2014). Livre para crescer: Sustentabilidade emocional, parentalidade com apego e Unschooling. [S.e.].

Zamboni, F. (2016). Contra a escola: Ensaio sobre literatura, ensino e educação liberal. Vide editorial.

Zamboni, F. (2020). A opção pelo homeschooling: Guia fácil para entender por que a educação domiciliar se tornou uma necessidade urgente em nossa época. Campinas: CEDET. 